\title{
Self-cannibalism in the Aegean wall-lizard, Podarcis erhardii
}

\author{
EVANTHIA THANOU* \& PANAGIOTIS KORNILIOS \\ Molecular Ecology Backshop, G. Lekka 16, 5th floor, Loutraki Korithia GR20300, Greece \\ Corresponding author Email: thanouevanthia@gmail.com
}

A utophagy - also called self-cannibalism - is a term used to describe the consumption of an animal's own body parts. Lizards, for example, may both lose and sometimes eat their own tails intentionally. Caudal autotomy or the self-amputation of the tail in lizards is an anti-predation strategy that helps these animals escape when caught by the tail. In some species, tails can also be shed in response to physical grasping during mating, as a result of male fighting (Arnold, 1984), or even in response to a stressful condition (Walter, 1962). Almost all lizards that perform autotomy can regenerate the lost tail after a short period of time (Arnold, 1984). Yet both losing a tail and regenerating it have negative consequences for the individual's locomotion (Lin et al., 2006), social interactions (Salvador et al., 1995), immune system (Argaez et al., 2018), and future body growth (Maginnis, 2006), which affect both survival and reproductive potential (Bateman \& Flemming, 2009). In compensation a lizard may return and eat its own tail, to regain some of the sacrificed resources which can then contribute towards the re-growth of the tail (Maginnis, 2006).
The first case of autophagy in the family Lacertidae was recently reported as a field observation on the Iberian rocklizard, Iberolacerta monticola (Iglesias-Carrasco \& Cabido, 2016). Here we report autophagy in another mediterranean endemic lacertid, the Aegean wall-lizard, Podarcis erhardii (Bedriaga, 1882). During field-work on 21 September 2018 we collected $P$. erhardii from Naxos Island $\left(37.037^{\circ} \mathrm{N}\right.$ $25.486^{\circ} \mathrm{E}$; Fig. 1) with the use of a rubber band fired at the lizards. This can stun the animals for a short period but they are unharmed and make a full recovery (Bennett, 1999). Captured lizards were placed individually in soft and dark fabric bags and then into a plastic container to allow recovery with as little stress as possible. Lizards were processed the next day for the collection of tissue, stomach-contents and their preparation as museum specimens for the Zoological Museum of the University of Patras (ZMUP).

In this process, we found one adult male specimen (museum voucher ZMUP523) to have shed its tail, more likely during transfer. The tail was actually broken in three parts (Fig. 1) and the two smaller ones were found intact in the animal's

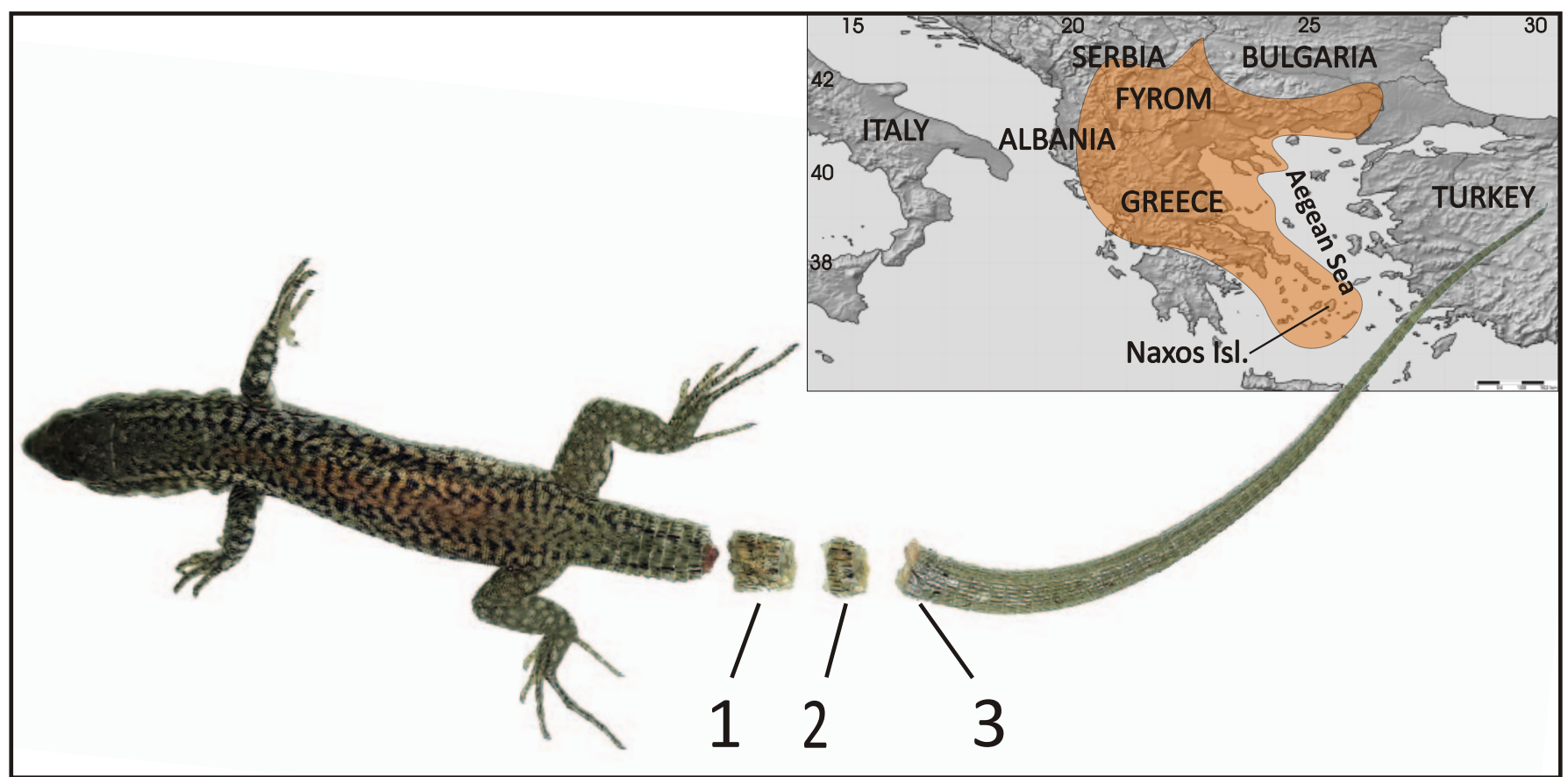

Figure 1. The $P$. erhardii specimen that exhibited self-cannibalism. There were no chewing marks on either of the two ingested pieces (marked 1 and 2 ) and the tail was restored to its full length when all parts (1-3) were aligned. Map shows the approximate distribution of the species and the sampling location of the specimen. 
stomach. We believe our observation raises three interesting points. First, autotomy was performed without the triggering effect of physical grasping and was most probably due to the stress of captivity. Secondly, autophagy still occurred despite that stress. Third, our observation corroborates previous suggestions that the consumption of the autotomised tail might be a common behaviour in lacertid lizards, although not an easy one to observe in nature. For I. monticola, this behaviour was associated with adaptation to alpine habitats (Iglesias-Carrasco \& Cabido, 2016). The Aegean insular populations of $P$. erhardii are also facing harsh environmental conditions, specifically prolonged drought, hot summers and a high rate of predation, and consequently are considered among those species that may readily apply autotomy as an attempt to escape predators (Pafilis et al., 2009). In these conditions, it is possible that regaining lost resources by consuming severed tails could have important survival value.

\section{ACKNOWLEDGEMENTS}

Fieldwork and collection were performed according to international standards and in compliance with the national legislation (Presidential Decree PD 67, 23/A/30-1-81) governing research on animals in Greece.

\section{REFERENCES}

Argaez, V., Solano-Zavaleta, I., Zúñiga-Vega, J.J. (2018). Another potential cost of tail autotomy: tail loss may result in high ectoparasite loads in Sceloporus lizards. Amphibia-Reptilia 39: 191-202.
Arnold, E.N. (1984). Evolutionary aspects of tail shedding in lizards and their relatives. Journal of Natural History 18: 127-169.

Bateman, P.W., Fleming, P.A. (2009). To cut a long tail short: a review of lizard caudal autotomy studies carried out over the last 20 years. Journal of Zoology 277: 1-14.

Bennett, D. (1999). Expedition Field Techniques: Reptiles and Amphibians. Royal Geographical Society, London, U.K. 95 pp.

Iglesias-Carrasco, M., Cabido, C. (2016). A case of tail autophagy in a male of the Iberian rock lizard, Iberolacerta monticola. Salamandra 52: 215-216.

Lin, Z., Qu, Y., Ji, X. (2006). Energetic and locomotor costs of tail loss in the Chinese Skink, Eumeces chinensis. Comparative Biochemistry and Physiology 143A: 508513.

Maginnis, T.L. (2006). The costs of autotomy and regeneration in animals: a review and framework for future research. Behavioral Ecology 17: 857-872.

Pafilis, P., Foufopoulos, J., Poulakakis, V., Lymberakis, P., Valakos, E. (2009). Tail shedding in island lizards (Lacertidae, Reptilia): decline of antipredator defenses in relaxed predation environments. Evolution 63: 12621278.

Salvador, A., Martin, J., Lopez, P. (1995). Tail loss reduces home range size and access to females in male lizards (Psammadromus algirus). Behavioral Ecology 6: 382-387.

Walter, R., (1962). The Reptiles and Amphibians of Southern Africa. Maskew Miller T., Cape Town, South Africa. 494 pp.

Accepted: 17 January 2019 